\title{
Climatic Changes and Effect on Wild Sheep Habitat
}

ild sheep are sensitive to
environmental change and
may be an effective indicator spe-
cies of climate change in arctic
and high mountain ecosystems. To
understand the effects of climatic
changes on Dall sheep habitat,
U.S. Geological Survey scientists
have been studying selected areas
in Alaska since 2007 . The research
focus is on forage quality, nutri-
ent levels, and changes resulting
from warming or cooling climate
trends. Preliminary results indi-
cate significant changes in Dall
sheep diet accompanying vegeta-
tion changes and upslope retreat
of glaciers.

\section{Climatic Changes and Effect on Wild Sheep Habitat}

To investigate the impact of climate changes on traditional habitat of high-mountain large animals, particularly Dall sheep, U.S. Geological Survey (USGS) scientists selected two initial study sites in Alaska - one within Denali National Park and the other south of Fairbanks at the headwaters of the Wood River. Major factors considered in selecting these sites included accessibility, known Dall Sheep populations, availability of prior research data, proximity to moderate-to-small size glacial systems, and conditions that would enable comparison between an undisturbed sheep population and a heavily managed and hunted population. Field work was conducted at the Denali National Park area each year from 2007 to 2011; the Wood River area was studied in 2008 and 2010.

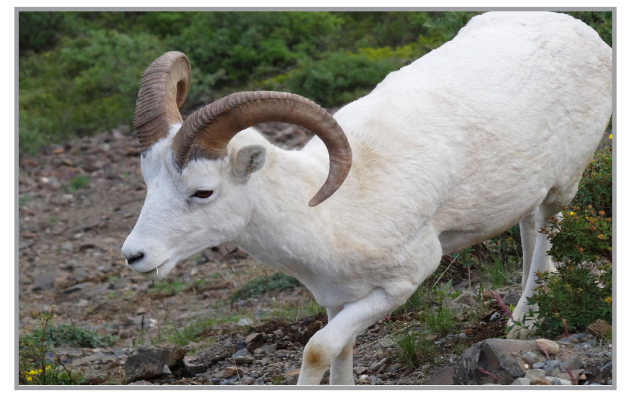

A Dall sheep feeding in typical habitat within Denali National Park field area.

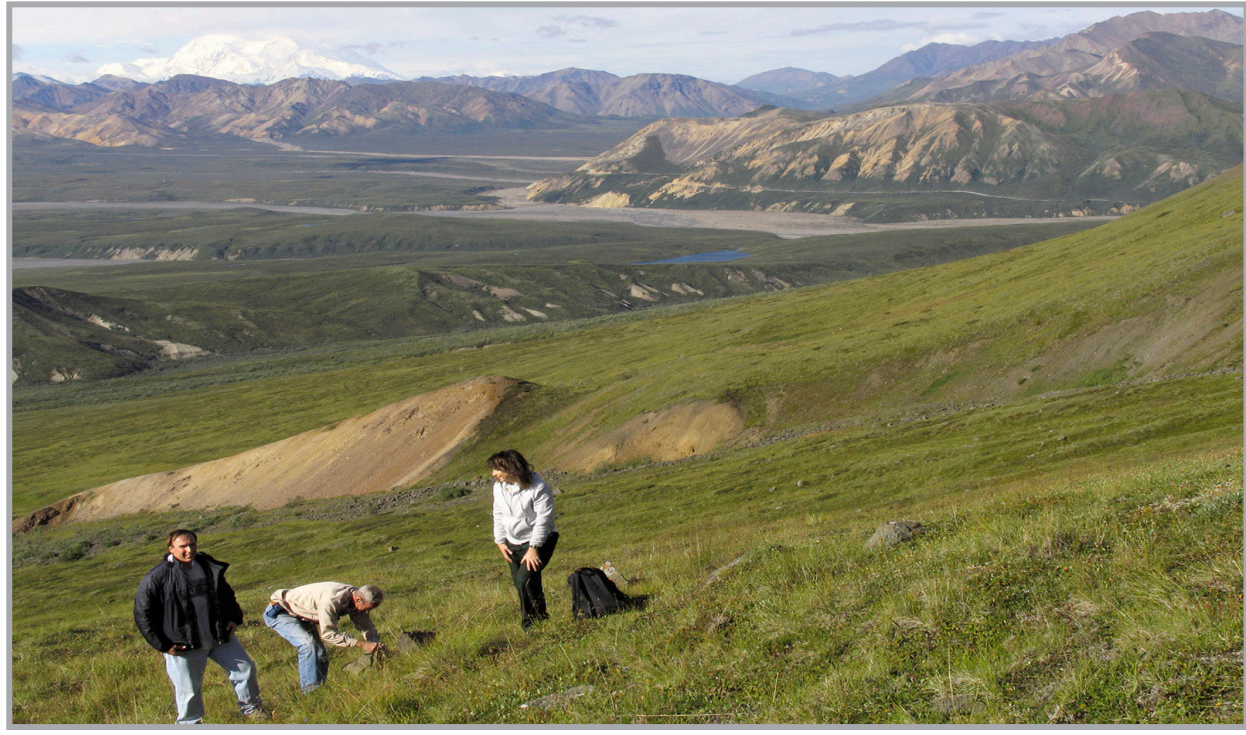

U.S. Geological Survey scientists collecting samples in Dall's sheep habitat, Denali National Park field area. In background, the massif of Denali (Mount McKinley) rises to 20,320 feet (6,194 meters).

\section{Research Approach}

Land-cover information for the study areas was primarily derived from a variety of remotely sensed data, ground-based observations, and existing historical databases. Landsat satellite imagery from 1979, 1987, 1994, 2000, and 2007 was used to determine areal extent and retreat of glaciers. Change-detection datasets and other products will assist in determining variability in land-ice coverage and in assessing its relation to the health and overall condition of the habitat. Historical aerial photography, topographic maps, and historical reports provide information on snow and ice distribution before the availability of satellite data.

Phenological changes in the landscape were analyzed using MODIS, Landsat, and Quickbird imagery. Phenology provides information on the integrated response of plant species to climate as reflected in the timing, intensity, and duration of vegetation greenness. Global Positioning System points were collected along transects and within distinct vegetation types to aid in developing land-cover maps of the study areas. Phenological, spatial, and structural metrics derived from these data help define and characterize the observed landscapes. In conjunction with earlier vegetation maps of Denali National Park, these data will enable vegetation changes in sheep habitat to be detected and evaluated.

Wild sheep feces were collected and analyzed for the nutrient value, digestibility, and vegetation-species composition of the sheep diet. In addition, water samples from snowfield melt, permafrost melt, and glacial streams were analyzed for nutrient levels.

By combining the field observations with satellite-based products, we will be able to develop a reliable model of habitat change. Analysis of remotely sensed data will be coupled with the fecal analysis to assess change in wild sheep forage and its relation to climate change. Evaluation of changes in the overall quality of wild sheep habitat based on the inferred nutritional value of each landscape type will provides a means to monitor habitat quality through time. Once a reliable set of baseline data has been collected and analyzed, models will be developed to predict changes that may occur in the health (nutrient level) of the habitat and forage resulting from changing climate conditions.

Most of the research and collection of field data is being done by USGS personnel from the Western Geographic Science Center and located in Flagstaff, Arizona. However, in 2008-2010 students in the Alaska Wildlands Program at the Wrangell Mountain Center collected vegetation information and Dall sheep feces samples in the Mill Creek Valley area of the Wrangell Mountains. Gretchen Roffler, USGS, Alaska Science Center, also collected Dall's sheep feces samples in the Wrangell Mountains in coordination with noninvasive genetics research.

\section{Research Results}

\section{Changes in glacial and snowfield extent}

Landsat imagery was used to measure changes in glacial margins from 1979 to 
1979 glacial extent

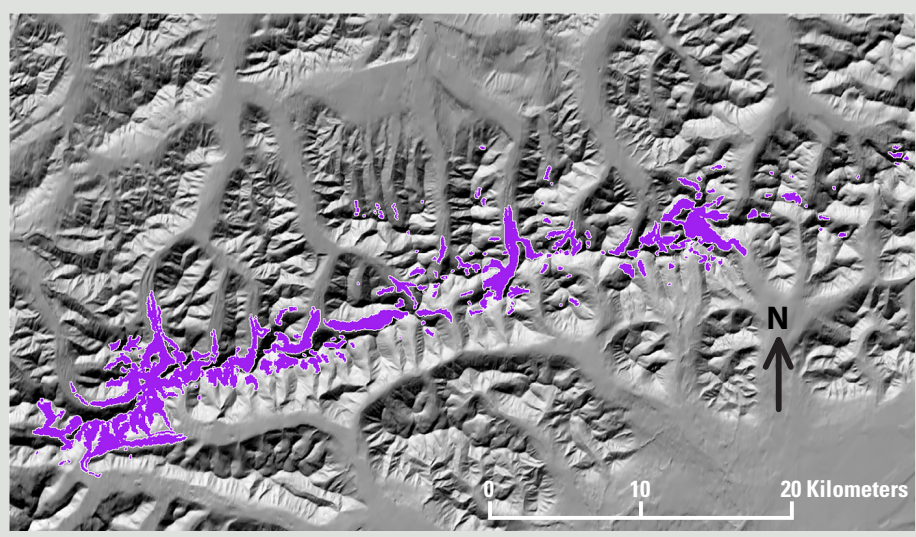

Mean elevation of glaciers: 5,977 feet $(3,448-8,783)$

Surface area: $104.2 \mathrm{~km}^{2}$
2007 glacial extent

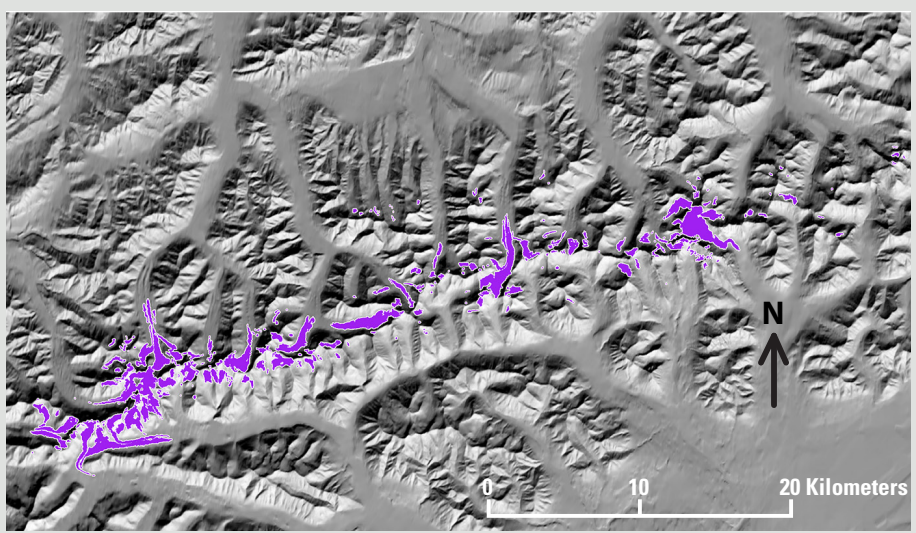

Mean elevation of glaciers: 6,110 feet

$(3,602-8,783)$

Surface area: $55.0 \mathrm{~km}^{2}$ (47\% decline)

On these images, the area of ice is shown in purple-the images show an approximately 47\% decline in glacial extent from 1979 to 2007.

2007 in the Denali National Park study area. Glaciers are shown in purple and indicate the extent of the glacial area that was studied-glaciers outside of the study area were included in order to provide more statistically significant sampling. Analyses showed that from 1979 to 2007 the mean elevation of the glaciers increased from 5,977 to 6,110 feet, an increase of 133 feet. During this same time the surface area of the mapped glaciers went from 104.2 to 55.0 square kilometers, a $47 \%$ decline (surface area calculations take topography into account).

\section{Fecal Analysis}

Wild sheep feces (pellets) are collected and analyzed for nutrient value, digestibility (stress), and forage species composition and change. Multiple collections are made at the same collection sites each field season, in order to evaluate changes over annual collections. Significant changes in Dall sheep diet occurred between 2007 and 2008. Although consumption of grasses was nearly identical

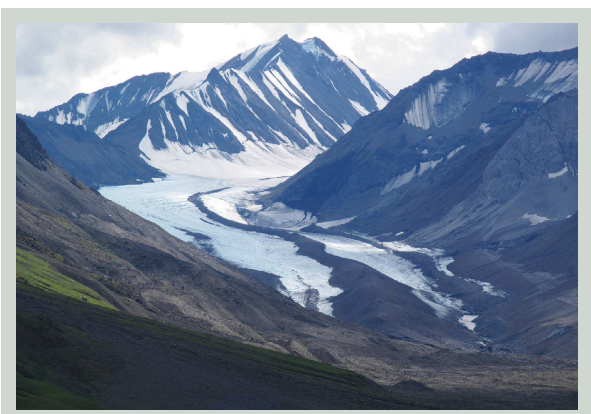

Partly glaciated Dall sheep habitat in high mountain country of the Denali National Park field area. both years, consumption of sedges, rushes, and shrubs showed a sharp decline in 2008 from 2007. Conversely, consumption of lichen, mosses, and forbs showed a significant increase in 2008 over 2007. No analysis of diet composition was performed in 2009 and 2010. However, Dall sheep pellets are being analyzed for diet composition in 2011 to see if these trends continue.

\section{Water Analysis}

Water samples were collected at Wood River (July 29-30, 2008) and Denali National Park (August 2, 2008; July 27-28, 2009; July 26, 2010; and August 2-3, 2011). The samples were analyzed in the USGS National Water Quality Laboratory (NWQL) in Denver, Colo., to determine organic and inorganic constituents.

Overall water analysis results showed low nutrient values at all sites with minimal change over time. This may have been because the samples were taken from locations where water was not mixed with soils long enough to pick up nutrients. Rainwater or water previously frozen in permafrost or glaciers would not have had the chance to absorb nutrients. Typically, water from ponds or lakes has the highest levels of nutrients, having had time to mix with soils and leafy material and absorb their nutrients.

\section{Future Research}

The observed changes in the preferred diet of Dall sheep between 2007 and 2008 are striking and suggest the need for continued analysis to determine causes and effects. Specifically, we plan to investigate the role that increased or decreased precipitation and temperature may have on this substantial change. Upslope movement of woody plants may also have a significant impact on Dall's sheep by encroaching into forage areas, preventing free movement between forage areas, and creating cover for large predators that feed on Dall sheep. Large areas of willow are dying out or already dead. What is causing this rather large willow die-off? Are temperature and precipitation factors in the willow die-off, as is suspected with changes in Dall sheep favored forage? We will investigate these questions in the next phase of our research.

\section{Contacts and Collaborators:}

Edwin L. Pfeifer (U.S. Geological Survey); Wayne Heimer (Alaska Department of Fish and Game, retired, and Wild Sheep Foundation, Cody, Wyo.); Gretchen Roffler (U.S. Geological Survey, Alaska Science Center); Raul Valdez (Department of Fisheries, Wildlife, and Conservation Ecology, New Mexico State University); Megan Gahl (Alaska Wildlands Studies Program at the Wrangell Mountains Center, McCarthy, Alaska)

\section{Edited by Peter H. Stauffer Graphic design by Stephen L. Scott}

COOPERATING ORGANIZATION National Park Service, Denali National Park

For more information contact:

Edwin L. Pfeifer, epfeifer@usgs.gov, (928) 853-4633 http://sgst.wr.usgs.gov/alaska

This Fact Sheet and any updates to it are available online at http://pubs.usgs.gov/fs/2012/3060/ 